\title{
LYOPHILIZED SURVIVAL MEDIUM FOR THE T. PALLIDUM IMMOBILIZATION TEST*
}

\author{
BY \\ L. J. BOREL, R. BENTEJAC, AND P. DUREL \\ WITH THE TECHNICAL ASSISTANCE OF \\ J. MARIEN \\ Dispensaire de Salubrité, Hôpital Saint-Lazare, Paris
}

The difficulties experienced in keeping $T$. pallidum alive for carrying out the immobilization test have led us to study during the last 4 years the possibility of ensuring the keeping quality of the survival medium by means of lyophilization. The dryfreezing method was discovered by Wurtz and Camus (1919). Storage of large quantities of the medium is thereby made possible without question of time limit, and with the following obvious advantages:

(1) More constant results are obtained and routine work is made easier.

(2) Research on the factors influencing survival is facilitated. The assured quality of the lyophilized product disposes of failures formerly attributed to defects in the medium. The difficulty of keeping $T$. pallidum alive involves only factors concerned with the extraction of the treponemes from the testicular tissue.

Recently, in order to have our figures confirmed, we invited workers in laboratories in France and elsewhere to undertake a combined study of this medium. We take this opportunity of thanking them for agreeing to do so. $\dagger$

\section{Material and Methods}

The composition of the lyophilized medium differs very little from that proposed by Nelson and Diesendruck (1952) and from that used in most of the laboratories that carry out the treponemal immobilization test (Table I). The advantages of including streptomycin (Borel and Daguet, 1955) and penicillinase are well known. In addition, we

* Paper read by Dr. P. Durel to the M.S.S.V.D. at Addenbrooke's Hospital, Cambridge, on July 5, 1958.

† Abroad: Copenhagen, Dr. Nielsen; London, Dr. Wilkinson; Vienna, Dr. Ehrmann.

IN France: Lyon (Prof. Sohier's laboratory), Dr. Thivolet; Paris Hospitals: (St. Louis) Dr. Daguet; (St. Lazare) Dr. Borel.
TABLE I

COMPOSITION OF LYOPHILIZED MEDIUM

\begin{tabular}{|c|c|c|c|c|}
\hline Product & & & & $\begin{array}{l}\text { Quantity of Medium } \\
\text { (per litre) }\end{array}$ \\
\hline $\begin{array}{l}\text { Sodium Thioglycollate } \\
\text { Cysteine H Cl } \quad . . \\
\text { Sodium Pyruvate } \quad . \\
\text { Glutathione .. } \\
\text { Dihydrostreptomycin } \\
\text { Human Albumin } \quad . \\
\text { Sodium Chloride .. } \\
\text { Potassium Acid Phosphate } \\
\text { Disodium Phosphate } \\
\text { Sodium Bicarbonate } \\
\text { Ultrafiltrate of Ox Serum } \\
\text { Penicillinase . . . . }\end{array}$ & $\begin{array}{l}\cdots \\
\cdots \\
\cdots \\
\cdots \\
\cdots \\
\cdots \\
\cdots \\
\cdots\end{array}$ & $\begin{array}{l}\cdots \\
\cdots \\
\cdots \\
\cdots \\
\cdots \\
\cdots \\
\cdots \\
\cdots\end{array}$ & $\begin{array}{l}\cdots \\
\cdots \\
\cdots \\
\cdots \\
\cdots \\
\cdots \\
\cdots \\
\cdots \\
\cdots\end{array}$ & $\begin{array}{r}500 \mathrm{mg} . \\
196 \mathrm{mg} . \\
156 \mathrm{mg} . \\
384 \mathrm{mg} . \\
1,000 \mathrm{mg} . \\
25,000 \mathrm{mg} . \\
6,180 \mathrm{mg} . \\
972 \mathrm{mg} . \\
1,773 \mathrm{mg} . \\
718 \mathrm{mg} . \\
50 \mathrm{ml} . \\
5 \mathrm{ml} .\end{array}$ \\
\hline
\end{tabular}

have substituted human for bovine albumin as a matter of convenience. This albumin which has been correctly lyophilized and is immediately soluble, is readily obtainable from all blood transfusion centres (where it is a by-product in the extraction of serum globulins) at a much lower price than that of bovine albumin. The quantity of ultra-filtrate of ox serum $\neq$ has been increased to improve the medium.

The preparation of a batch of medium for lyophilization differs in no way from that of ordinary medium. At St. Lazare we use the following technique in preparing one litre of the medium.:

(i) The albumin is dissolved in approximately $400 \mathrm{ml}$. water double-distilled in an all-glass still. $\S$

(ii) The other constituents are mixed in a second container with $400 \mathrm{ml}$. double-distilled water until they are completely dissolved.

(iii) The two solutions are then mixed in a graduated flask and the volume is made up to exactly one litre.

(iv) Thus prepared, the medium is filtered under pressure in a Seitz filter (model E.K. 14), which has a two-litre porcelain chamber fitted with a bacterial

‡ Ultrafiltrate of horse serum can be substituted for ox serun: (Hardy, personal communication).

If necessary the pH is adjusted to $7 \cdot 1$ by means of decinormal sodium hydroxide. 
filter-plate (E.K.S.2). The filtration takes from 10 to 15 minutes, and the whole process should be completed within 90 minutes.

After filtering, the medium is poured into ampoules with a capacity of $30 \mathrm{ml}$., each ampoule containing $10 \mathrm{ml}$., and immediately frozen in a thin layer by centrifuging in a mixture of alcohol and dry ice. Once this lyophilization has been completed, the ampoules are sealed in vacuo. When the medium is required for use all that is necessary is to open an ampoule and introduce into it the appropriate quantity of sterilized double-distilled water.

\section{Results}

Before undertaking the study of the lyophilized medium, we carried out trials to establish:

(1) That lyophilization of the medium did not interfere with its ability to keep the treponemes alive.

(2) That the lyophilized medium remained stable for an indefinite length of time at room temperature.

The effect of lyophilization on the viability of the treponemes was studied with batches of medium, half having been lyophilized and stored at the temperature of the laboratory, and half having been kept at $-20^{\circ}$., as is usual for the TPI test. Table II shows the keeping quality of lyophilized medium; 15 months after its manufacture it proved to be of excellent quality.

TABLE II

COMPARATIVE PERCENTAGES OF SURVIVAL TIMES OF $T$. PALLIDUM OVER A PERIOD OF 15 MONTHS IN THE SAME MEDIUM, BOTH LYOPHILIZED AND NON-LYOPHILIZED

\begin{tabular}{l|c|c|c|c|c|c|c|c|c|c|c}
\hline \multirow{2}{*}{$\begin{array}{c}\text { Media } \\
\text { (Batch 1411) }\end{array}$} & \multicolumn{6}{|c|}{ Delay in Use after Manufacture } \\
\cline { 2 - 7 } & 2 & 5 & 12 & 15 & 2 & $2 \frac{1}{2}$ & $2 \frac{1}{2}$ & 4 & 6 & 8 & 15 \\
\hline $\begin{array}{l}\text { Lyophilized } \\
\text { (kept at labora- } \\
\text { tory tempera- } \\
\text { ture) }\end{array}$ & 100 & 100 & 84 & 92 & 96 & $14^{*}$ & 92 & 88 & 100 & 82 & 98 \\
\hline $\begin{array}{l}\text { Non-lyophilized } \\
\text { (kept at - 20 }\end{array}$ & 100 & 100 & 96 & 100 & 86 & $0 *$ & 76 & 30 & 0 & 0 & - \\
\hline
\end{tabular}

These results show the percentage of survival $22 \mathrm{hrs}$ after incubation in tubes of media containing only the suspension of treponema. * The failure in this test, repeated the following day under identical conditions, is a good illustration of the importance of survival or toxic factors in the testicular fluid.

It only remained to confirm that each batch of lyophilized medium could be depended on to give uniform results. Of six batches, only one was found to be unsatisfactory after being kept at room temperature for a month. This particular batch had been lyophilized in flasks, the kind used at blood transfusion centres, each having a volume of $50 \mathrm{ml}$. Such a flask would be ideal for routine testing of some forty to fifty sera. It is possible to use it for preparing the suspension of Treponema pallidum and its rubber stopper facilitates evacuation and filling with nitrogen $+\mathrm{CO}_{2}$. Unfortunately the rubber stopper is not sufficiently air-tight, and contact with surrounding atmosphere rapidly brought about alterations in the medium.

We then sought to compare our own first findings with those from other laboratories. We have been able to send out only two batches of lyophilized medium, one prepared one month before despatch and the other 6 months before despatch. Because of the risk of deterioration in transit, we sent out no unlyophilized batches.

The results obtained are set out in Figs 1 and 2 (opposite). Fig. 1 shows the averages of three tests made to ascertain the percentage survival of treponemata after $22,30,44,60$, and 72 hours, with T.P. suspension Batch 611 of the medium (prepared 1 to 2 months before the tests were made in the various laboratories).

Fig. 2 gives the results of a single trial at each laboratory with a batch of medium 6 months old.

The results shown in Figs 1 and 2 are summarized in Table III, which sets out the results of tests with lyophilized media (Batches 611 and 295) obtained by the laboratories taking part in the co-operative study. $\uparrow$

TABLE III

RESULTS OF TESTS WITH LYOPHILIZED MEDIA IN TUBES CONTAINING ONLY THE SUSPENSION OF TREPONEMATA

\begin{tabular}{|c|c|c|c|c|}
\hline \multirow{2}{*}{ Batch Number } & \multirow{2}{*}{$\begin{array}{l}\text { Incubation } \\
\text { Period (hrs) }\end{array}$} & \multirow{2}{*}{ No. of Tests } & \multicolumn{2}{|c|}{ Results } \\
\hline & & & Satisfactory & Poor \\
\hline 611 & $\begin{array}{l}22 \\
30 \\
44\end{array}$ & $\begin{array}{l}15 \\
14 \\
13\end{array}$ & $\begin{array}{r}13 \\
10 \\
6\end{array}$ & $\begin{array}{l}2 \\
4 \\
7\end{array}$ \\
\hline 295 & $\begin{array}{l}22 \\
30 \\
44\end{array}$ & $\begin{array}{l}6 \\
6 \\
6\end{array}$ & $\begin{array}{l}3 \\
5 \\
3\end{array}$ & $\begin{array}{l}3 \\
1 \\
3\end{array}$ \\
\hline
\end{tabular}

We have arbitrarily defined as "satisfactory" those tests which show a survival rate of over 80 per cent. after 22 hours incubation, of 60 per cent. after 30 hours, and of over 60 per cent. after 44 hours. The fact that with Batch 295 there were more satisfactory results after 30 hours than after 22 hours is accounted for by two of the tests which gave identical results after 30 hours, having shown survival rates of 60 and 70 per cent. after 22 hours. In the laboratories where unsatisfactory survival rates were obtained, it was found that the addition to the medium of serum, complement, or ultra-filtrate brought the figures up to normal. By using the same

\footnotetext{
† Details will be given in WHO circular to TPI Laboratories.
} 


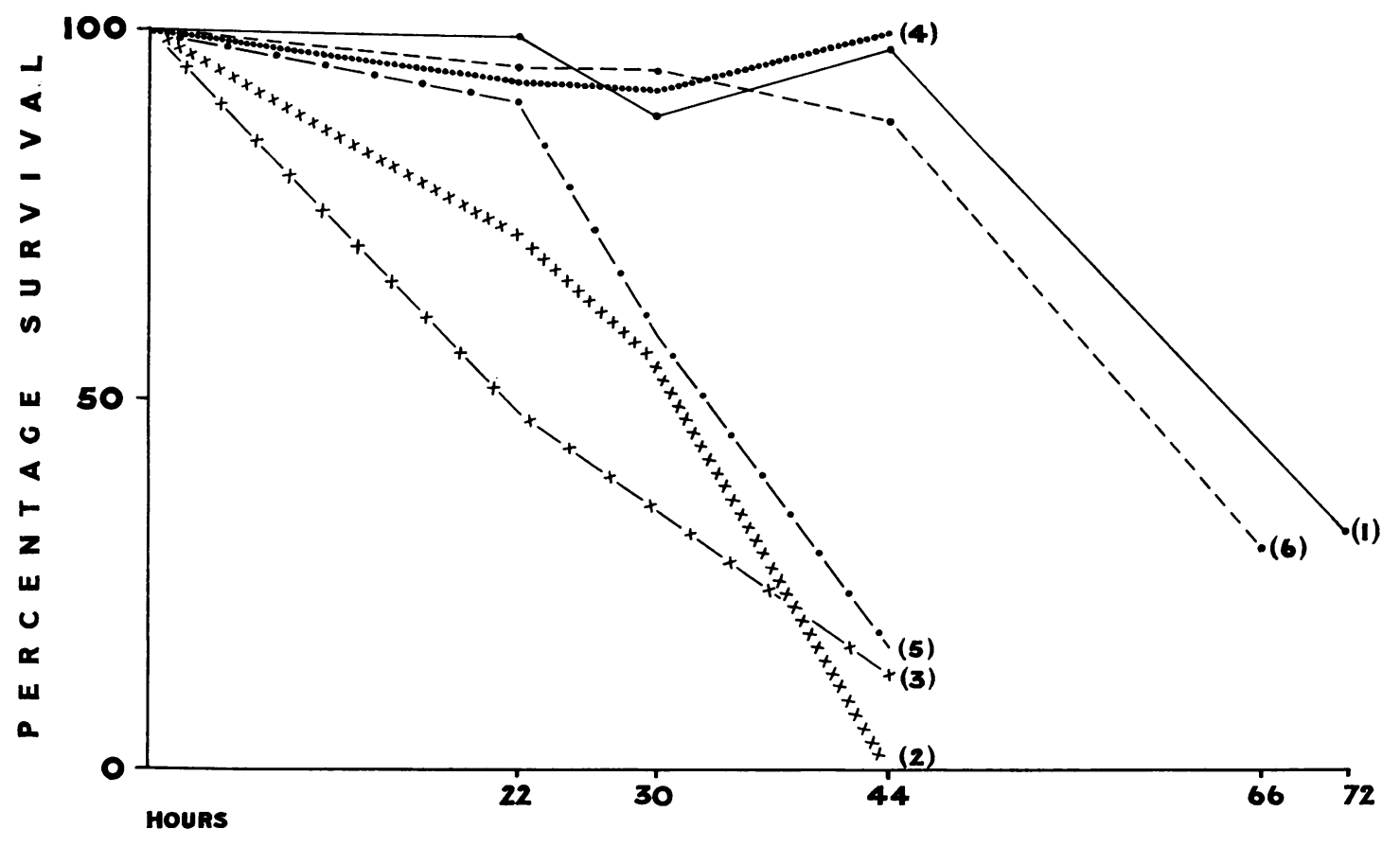

FIG. 1.-Survival rates in six laboratories using Batch 611

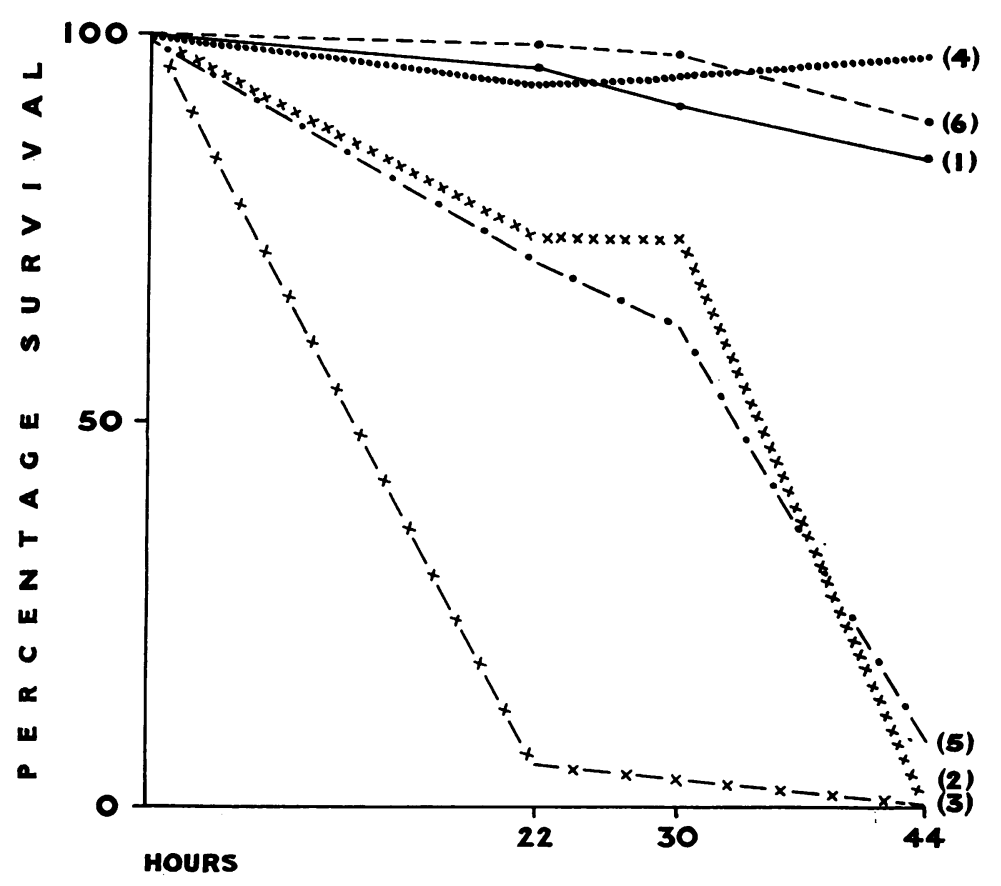

FIG. 2.-Survival rates in six laboratories using Batch 295. 
criteria but taking into consideration tubes containing the medium plus one or other of those supplements, the results shown in Table IV were obtained. Table IV differs from Table III only in the last two columns, which show the results of the tests when serum, complement, or ultrafiltrate is added to the medium.

TABLE IV

RESULTS OF TESTS WITH ADDED SERUM, COMPLEMENT OR ULTRAFILTRATE

\begin{tabular}{c|c|c|c|c}
\hline Batch Number & $\begin{array}{c}\text { Incubation } \\
\text { Period (hrs) }\end{array}$ & No. of Tests & \multicolumn{2}{|c}{ Results } \\
\hline \multirow{2}{*}{611} & 22 & 15 & Satisfactory & Poor \\
\hline 30 & 14 & 14 & 1 \\
& 44 & 13 & 12 & 0 \\
\hline 295 & 22 & 6 & 6 & 0 \\
& 30 & 6 & 6 & 0 \\
& 44 & 6 & 5 & 1 \\
\hline
\end{tabular}

The sera (positive controls or sera which were known to be positive or negative) examined with these media gave results identical with those obtained with media not lyophilized; this is true of all the laboratories concerned. We have personally examined more than 250 sera, using in each case both lyophilized and non-lyophilized media, without finding the slightest difference in the results. Finally, the residual complement, when it has been recovered by means of haemolysis, has invariably been found to be excellent. Some laboratories have reported that this medium was superior to or identical with their own; others found that it was not so good.

\section{Discussion}

Before embarking on a discussion, we feel we must comment on the manner in which the trials were carried out. The conditions were not those essential for routine TPI testing. We have noticed, as have workers at other laboratories on a number of occasions, that the use of small volumes of medium has given poor survival rates of $T$. pallidum; and this is all the more likely if in obtaining the treponemata one has to use fragments instead of whole testes, and for this reason the use of whole testes is recommended. Unfortunately, the quantities of medium at our disposal were insufficient to enable us to distribute to each laboratory what would be an ideal amount, that is to say 40 to $50 \mathrm{ml}$. for each test. Nevertheless, the results appear to be sufficiently clear-cut for discussion. The following points may be made:

(i) That the results were good in the majority of the laboratories testing them.

(ii) That some laboratories did not regularly obtain satisfactory survival rates. (iii) That with each lyophilized medium each laboratory had at the worst one satisfactory test out of three. No laboratory had only failures.

The results from laboratories selected because of their known technical excellence pose a problem which we have long been unable to solve: that some poor survival rates are due to factors unconnected with the medium. The use of lyophilized medium makes a study of these factors possible.

One of the principal advantages of lyophilization is to ensure the perfect preservation of any substance. From the moment that a product can be lyophilized without changing its properties, it preserves its own identity indefinitely. Experience shows that TPI medium is no exception to this rule. The proportion of unsatisfactory tests after 22 hours' incubation for Batches 611 and 295 is five out of 21 in tubes containing the testicular emulsion alone, and only one out of 21 in tubes to which complement had been added: which is the same as was found in identical media that had not been lyophilized.

As regards the quality of the lyophilized survival medium, it obviously can be no better than that of the same batch that has not been lyophilized. That is why we make no claim to have devised an outstanding medium; for we have merely increased the keeping properties and facilitated the use of a medium which we have used routinely for several years. We are satisfied that some laboratories taking part in this study work with media superior to our own and in this connection we would express our willingness to test other formulae and subject them to lyophilization, should the opportunity arise.

Lyophilization simplifies routine work and also makes it easier to detect the failure of one of the factors promoting survival of the treponemata hy eliminating the variable quality of the medium.

This brings us to a brief survey of those factors which have a bearing on survival of the treponemata in work on the TPI test:

(i) The extent to which completely anaerobic conditions have been ensured.

(ii) The quality of the survival medium.

(iii) The degree of success in inducing an acute orchitis.

(i) This factor ought to be the simplest to control (by passing a mixture of gases over red-hot copper to get rid of any oxygen that it might contain: and confirming the absence of oxygen by putting gas through a solution of sodium pyrogallate).

(ii) In cases where survival rate has been poor, the quality of the medium has often been questioned. With lyophilized medium this problem no longer arises. 
(iii) There remains only the nature of the orchitis on which to fasten the blame for poor results. This well might te the subject of joint study by several laboratories, using the same technique, the same batch of medium, the same sera, and the same complement, all of which have been lyophilized, and this study is to be organized in the months to come. In this way the effects could be examined of the following factors:

(a) Strain, age and weight of the animal;

(b) Amount, volume, and vehicle of the inoculum;

(c) Duration and severity of the induced orchitis.

It is clear that testicular fluid possesses a factor influencing the survival time of treponemes in culture medium. Depending on the quality of the orchitis from which the fluid is obtained, this factor will be more or less active, and the survival time will range from excellent to none at all. It is also probable that in some cases the testicular extract contains a toxic

TABLE $\mathrm{V}$

INFLUENCE OF TESTICULAR FLUID ON SURVIVAL TIME OF T. PALLIDUM

\begin{tabular}{l|c|c|c}
\hline \multicolumn{1}{c|}{$\begin{array}{c}\text { Tubes } \\
\text { containing }\end{array}$} & \multicolumn{2}{|c}{ Testicular Fluid } \\
\cline { 2 - 4 } & Survival Factor & $\begin{array}{c}\text { Contains } \\
\text { a Toxic } \\
\text { Factor }\end{array}$ \\
\hline Emulsion & Excellent & $\begin{array}{c}\text { Absent } \\
\text { Irregular, or } \\
\text { Insufficient }\end{array}$ & $\begin{array}{c}\text { Insufficient } \\
\text { or Nil }\end{array}$ \\
\hline $\begin{array}{l}\text { Emulsion }+ \\
\text { Serum or Complement } \\
\text { or Ultrafiltrate }\end{array}$ & Excellent & Excellent & $\begin{array}{c}\text { Irregular or } \\
\text { Insufficient }\end{array}$ \\
\hline
\end{tabular}

factor. Our views on this subject are summarized in Table V.

Failures with lyophilized media are attributable to the animal and not to any fault in the media which continue to give excellent results. Short survival times due to the composition of the testicular fluid may be made good by adding complement or serum, but such additions are not always successful in overcoming the toxic factor.

\section{Conclusion}

Lyophilization in no way alters the nutritive quality of the medium used in the TPI test. It ensures that the medium has perfect keeping properties and that the work is facilitated by the knowledge that the quality of the medium is constant. The only remaining variable is therefore the quality of the orchitis. One can use the medium as a standard either for starting work in a new laboratory, or for solving the problems of maintaining the treponemata alive which arise from time to time even in laboratories well-versed in the techniques of the TPI test.

Further, in order to reduce the difficulties of TPI routine work, it would seem desirable that lyophilized medium should be made available commercially for the benefit of laboratory workers interested in this field.

\section{REFERENCES}

Borel, L. J., and Daguet, G. (1955). Arch. Biol. méd., Suppl. Sem Hôp. Paris, $31,38$.

Nelson, R. A., and Diesendruck, J. A. (1951). J. Immunol., 66, 667. Wurtz, R., and Camus, L. (1919). Bull. Acad. Méd., 82, 12. 